\title{
Lethal and sublethal effects of toxicants on bumble bee populations: a modelling approach
}

\author{
J. E. Banks ${ }^{1}{ }^{1} \cdot$ H. T. Banks ${ }^{2} \cdot$ N. Myers ${ }^{2} \cdot$ A. N. Laubmeier ${ }^{2,4} \cdot$ R. Bommarco ${ }^{3}$
}

Accepted: 4 January 2020 / Published online: 14 February 2020

(c) The Author(s) 2020. This article is an open access publication

\begin{abstract}
Pollinator decline worldwide is well-documented; globally, chemical pesticides (especially the class of pesticides known as neonicotinoids) have been implicated in hymenopteran decline, but the mechanics and drivers of population trends and dynamics of wild bees is poorly understood. Declines and shifts in community composition of bumble bees (Bombus spp.) have been documented in North America and Europe, with a suite of lethal and sub-lethal effects of pesticides on bumble bee populations documented. We employ a mathematical model parameterized with values taken from the literature that uses differential equations to track bumble bee populations through time in order to attain a better understanding of toxicant effects on a developing colony of bumble bees. We use a delay differential equation (DDE) model, which requires fewer parameter estimations than agent-based models while affording us the ability to explicitly describe the effect of larval incubation and colony history on population outcomes. We explore how both lethal and sublethal effects such as reduced foraging ability may combine to affect population outcomes, and discuss the implications for the protection and conservation of ecosystem services.
\end{abstract}

Keywords Hymenoptera $\cdot$ Neonicitinoid $\cdot$ Delay differential equation

\section{Introduction}

The protection of ecosystem services has become a major focus of applied ecology, with one emphasis on understanding population processes of pollinators and biological control agents. Pollinator conservation in particular has received much attention due to their well-documented decline coupled with their ability to significantly contribute

Supplementary information The online version of this article (https:// doi.org/10.1007/s10646-020-02162-y) contains supplementary material, which is available to authorized users.

J. E. Banks

jebanks@csumb.edu

1 Undergraduate Research Opportunities Center, California State University, Monterey Bay, Seaside, CA 93955, USA

2 Center for Research in Scientific Computation, North Carolina State University, Raleigh, NC 27695-8212, USA

3 Department of Ecology, Swedish University of Agricultural Sciences, Uppsala 750 07, Sweden

4 Present address: Department of Mathematics, University of Nebraska-Lincoln, Lincoln 68588-0130 NE, USA to crop pollination (Klein et al. 2007; Wratten et al. 2012). Globally, chemical pesticides (especially the class known as neonicotinoids) have been implicated in hymenopteran decline (Desneux et al. 2007; Goulson et al 2015; Lundin et al. 2015; Rundlöf et al. 2015). Exposure to pesticides has been implicated in deficits in both short- and long-term learning as well as memory and sensory capabilities, all of which can affect foraging efficiency and provisioning (Tan et al. 2015; Klein et al. 2017). Within-colony behavior related to caretaking, which can have implications for thermoregulation and colony survival, may also be affected by pesticide exposure (Crall et al. 2018). Despite our increased understanding of the effects of pesticide exposure on bee physiology and behavior, the overall effects of pesticides on population dynamics of bees remain poorly understood. Furthermore, much of what we do know about population processes of pollinators stems from work conducted with honeybees (Apis melifera); recent simulation models have identified the potential for sublethal effects on honeybees stemming from varroa mites and other stressors (Becher et al. 2014; Thorbek et al. 2017), while other models have underscored the complex relationships between food availability and honeybee foraging and survival (Khoury et al. 2013; Perry et al. 2015). 
More recently, attention has increasingly focused on non-Apis bees, especially wild bees. In particular, declines and shifts in community composition of bumble bees (Bombus spp.) have been documented in North America and Europe (Biesmeijer et al. 2006; Bommarco et al. 2011; Bartomeus et al. 2013). A suite of lethal and sub-lethal effects of pesticides on bumble bee populations have been demonstrated, including reductions in foraging ability and other behavioral changes (Brittain and Potts 2011; Feltham et al. 2014; Barbosa et al. 2015; Stanley et al. 2016; Switzer and Combes 2016; Phelps et al. 2018; Lämsä et al. 2018). A population-level perspective is critical in linking what we know about individual toxicant effects to the long-term effects of pesticide exposure on bumble bee populations.

Pesticide risk assessment in the United States for all arthropods is based on acute toxicity tests $\left(\mathrm{LC}_{50}\right)$ on a single species-the European honeybee (A. mellifera)—making that organism an ideal starting point for understanding the effects of chemical stressors for other bees. However, we have shown that, due to subtle differences in life histories, even closely related hymenopteran species can exhibit markedly different population responses to the same toxic insults (Banks et al. 2011; Banks et al. 2014). Further complicating matters, work done at the physiological level reveals that different bee species exhibit different levels of susceptibility to the same chemical pesticides (Manjon et al. 2018). Taken together, what we know about the effects of toxicants on one species (e.g., honeybees) does not necessarily translate to a good understanding of the effects of toxicants on other even closely related species such as bumble bees; responses to toxicants need to be evaluated for each species. Furthermore, it is now well established that acute tests such as $\mathrm{LC} / \mathrm{LD}_{50}$, historically the gold standard for comparing toxicological effects, fail to capture longerterm population outcomes (including sublethal effects) and could be woefully misleading (Banks and Stark 1998; Stark and Banks 2003; Stark et al. 2004; Desneux et al. 2007; Forbes et al. 2011; Biondi et al. 2013; Stark et al. 2015). Finally, most studies of chemical toxicity related to bumble bees have focused on a single toxicant or pesticide, when in practice in the field bees are subjected to multiple toxicants acting in both lethal and sublethal ways (Stark et al. 2007). Here we seek a better understanding of toxicant effects on a developing colony of bumble bees over time, as well as insights into how acute and sublethal effects (either from the same or different chemical toxicants) may combine to affect population outcomes.

The utilization of computational models in bumble bee research has increased in recent years although it still has not been as exhaustive as efforts on honeybees. Many models have focused on foraging dynamics by workers as they influence different metrics of colony growth (Oster 1976; Olsson et al. 2015; Crone and Williams 2016;
Häussler et al. 2017). Becher et al. (2018) used agent-based modeling to understand hive dynamics, examining the influence of pesticides on multi-generational colony dynamics, though they did not explore effects on colony interior dynamics. Other similar models indicate that pesticides and other stressors can impact colony dynamics, for example by impairing worker bee productivity (Bryden et al. 2013) or queen fecundity (Cresswell 2017). These studies rely on differential and difference equations, in which changes to the colony at any time depend on the current state of the colony. However, changes to a colony might also depend on prior states of the colony, for example due to the length of larval incubation or history of resource availability. We describe these dependencies with a delay differential equation model, parameterized with values taken from the literature.

\section{Methods and materials}

We modelled a single colony of bumble bees using a nonlinear system of delay differential equations (DDE) that describe twelve state variables: in-nest nectar abundance $N$ $(t)$, in-nest pollen abundance $P(t)$, workers $W(t)$ and their larvae (modeled as a two-stage population, $\mathrm{L}^{(\mathrm{w})}{ }_{1}, \mathrm{~L}^{(\mathrm{w})}{ }_{2}$ ), males and their larvae (modeled as a two-stage population, $\left(\mathrm{L}^{(\mathrm{m})}{ }_{1}, \mathrm{~L}^{(\mathrm{m})}{ }_{2}\right)$, and gynes (new queens) and their larvae (modeled as a three-stage population, $\left.\left(\mathrm{L}^{(\mathrm{g})}{ }_{1}, \mathrm{~L}^{(\mathrm{g})}{ }_{2}\right), \mathrm{L}^{(\mathrm{g})}{ }_{3}\right)$.

The model describes the development of the reproductive classes by means of critical colony functions such as resource management, worker caregiving, and population control. It utilizes larval development as the link between colony resources and the adult bumble bee members. Parameter values were drawn from published studies on Bombus terrestris and the model was simulated by a direct application of MATLAB delay differential equation solver, dde223, to the mathematical model (MATLAB 2016a; Shampine and Thompson 2001). All parameters (Table 1) and full mathematical model (Appendix I) are provided.

The time frame for the simulated colony begins 22 days after hive initiation in the spring, where day 0 is the first day of spring, $T_{\mathrm{s}}$, when the first brood of workers emerge to begin gathering nectar and pollen as well as larval feeding and ejection (if necessary) until the beginning of winter when hive functions cease. The switch time, which represents the time when a colony changes from producing worker offspring to male and gyne offspring, is a distinguishing event in a colony's development (Duchateau and Velthuis 1988). We fixed a late switch time at $T^{*}=40$, so that male and gyne larvae appear at day 44, coincidentally the same day the last worker eggs are laid. Development times for each larval subclass was assumed to be fixed (see 
Table 1 Model variables and parameters. The selected value for simulations and attributions are given in the last column

\begin{tabular}{|c|c|c|c|}
\hline Variable & Description & Units & Estimate \\
\hline$t$ & Time & Days & \\
\hline$N(t)$ & Amount of in-nest nectar & $\mathrm{ml}$ & \\
\hline$P(t)$ & Amount of in-nest pollen & $\mathrm{g}$ & \\
\hline$W(t)$ & Number of workers & $\begin{array}{l}\text { Individuals } \\
\text { (workers) }\end{array}$ & \\
\hline$L_{1}^{(w)}(t), L_{2}^{(w)}(t)$ & Number of worker larvae & Individuals (larvae) & \\
\hline$M(t)$ & Number of males & Individuals (males) & \\
\hline$L_{1}^{(m)}(t), L_{2}^{(m)}(t)$ & Number of male larvae & Individuals (larvae) & \\
\hline$G(t)$ & Number of gynes & Individuals (gynes) & \\
\hline$L_{1}^{(g)}(t), L_{2}^{(g)}(t), L_{3}^{(g)}(t)$ & Number of gynes larvae & Individuals (larvae) & \\
\hline \multicolumn{4}{|l|}{ Timeline } \\
\hline$T_{s}$ & First day of spring & & 0 \\
\hline$T_{s}+22$ & First workers emerge & & $\begin{array}{l}22 \text { (Duchateau and Velthuis } \\
\text { 1988) }\end{array}$ \\
\hline$T^{*}$ & $\begin{array}{l}\text { First day male/gynes } \\
\text { eggs laid }\end{array}$ & & 40 (Müller et al. 1992) \\
\hline$T^{* *}$ & End of worker eggs laid & & 44 (Müller et al. 1992) \\
\hline$T_{W}$ & Beginning of winter & & 120 \\
\hline \multicolumn{4}{|l|}{ Parameters } \\
\hline$b_{N W}$ & $\begin{array}{l}\text { Worker nectar } \\
\text { collection rate }\end{array}$ & $\frac{\mathrm{ml}}{\text { day*individual }(\mathrm{W})}$ & $\begin{array}{l}0.6 \text { (Goulson et al. 2002; Peat } \\
\text { Goulson 2005) }\end{array}$ \\
\hline$b_{P W}$ & $\begin{array}{l}\text { Worker pollen } \\
\text { collection rate }\end{array}$ & $\frac{\mathrm{g}}{\text { day*individual }(\mathrm{W})}$ & $\begin{array}{l}0.4 \text { (Goulson et al. 2002; } \\
\text { Feltham et al. 2014) }\end{array}$ \\
\hline$\mu_{N W}$ & $\begin{array}{l}\text { Worker nectar } \\
\text { consumption rate }\end{array}$ & $\frac{\mathrm{ml}}{\text { day*individual }(\mathrm{W})}$ & 0.35 (Tasei et al. 2000) \\
\hline$\mu_{P W}$ & $\begin{array}{l}\text { Worker pollen } \\
\text { consumption rate }\end{array}$ & $\frac{g}{\text { day*individual }(\mathrm{W})}$ & 0.25 (Tasei et al. 2000) \\
\hline$c_{i}$ & $\begin{array}{l}\text { Larval pollen } \\
\text { consumption rates }\end{array}$ & $\frac{g}{\text { day*individual }(\mathrm{L})}$ & $(0.01,0.25)$ (Ribeiro 1994) \\
\hline$b_{W}(t)$ & Worker birth rate & $\frac{\text { workers }}{\text { day }}$ & $\begin{array}{l}8.5 \text { (Duchateau and Velthuis } \\
1988 \text { ) }\end{array}$ \\
\hline$b_{M}(t)$ & Male birth rate & $\frac{\text { males }}{\text { day }}$ & $\begin{array}{l}2 \text { (Duchateau and Velthuis } \\
1988)\end{array}$ \\
\hline$b_{G}(t)$ & Gyne birth rate & $\frac{\text { gynes }}{\text { day }}$ & $\begin{array}{l}2.6 \text { (Duchateau and Velthuis } \\
1988 \text { ) }\end{array}$ \\
\hline$\mu_{W}$ & Worker death rate & $\frac{1}{\text { day }}$ & 0.05 \\
\hline$Z$ & Larvae to worker ratio & & $\begin{array}{l}4 \text { (Duchateau and Velthuis } \\
1988 \text { ) }\end{array}$ \\
\hline$\alpha$ & $\begin{array}{l}\text { Max ejection rate } \\
\text { (negligence) }\end{array}$ & $\frac{\text { individual }(\mathrm{L})}{\text { day*individual }(\mathrm{W})}$ & 0.75 \\
\hline$\beta$ & $\begin{array}{l}\text { Max ejection rate } \\
\text { (malnutrition) }\end{array}$ & $\frac{\text { individual }(\mathrm{L})}{\text { day } * \text { individual }(\mathrm{W})}$ & 0.75 \\
\hline$\in$ & Roundoff correction factor & & 0.001 \\
\hline
\end{tabular}

Table 2, Appendix 1). We note that larvae were subdivided into age groups and we assumed that consumption was constant across each age group, with nectar being consumed at twice the rate of pollen (Pereboom 2000). The model we built was a system of delay differential equations (DDE's) which is appropriate to use in age structured population models (Murdoch et al.,1987; Hartung et al. 2006; Banks 2012; Banks et al. 2017). The model included time varying larval mortality rates $\left(\mu^{(w)}(t), \mu^{(m)}(t), \mu^{(g)}(t)\right)$ which were based on past values of the workers, pollen, and nectar variables. The DDE system tracks cumulative larval mortality rates through the $\Phi^{(w)}(t), \Phi^{(m)}(t)$, and $\Phi^{(g)}(t)$ variables, allowing us to calculate the development of broods independent of each other over a continuous spectrum, something that is not possible with ordinary differential equations. The larval mortality rate represents the rate at 
Table 2 Fixed duration (in days) of bumble bee life stages in model

\begin{tabular}{lllllll}
\hline Class & Egg & $L_{1}^{k}$ & $L_{2}^{k}$ & $L_{3}^{k}$ & Pupa & Total age \\
\hline Worker & 4 & 6 & 3 & - & 9 & 22 \\
Male & 4 & 8 & 3 & - & 11 & 26 \\
Gyne & 4 & 5 & 4 & 4 & 13 & 30 \\
\hline
\end{tabular}

which larvae are ejected from the hive per worker based on two conditions: whether or not there are sufficient resources to nourish existing larvae, and whether or not enough workers are present to tend to the larvae (Pomeroy 1979; Genisse et al. 2002; Tasei and Aupinel 2008; Roger et al. 2017). Estimating these values required a comparison between projected pollen consumption $\left(C=c_{1}\left(\mathrm{~L}^{(\mathrm{w})}{ }_{1}+\mathrm{L}^{(\mathrm{m})}\right.\right.$ $\left.\left.{ }_{1}+\mathrm{L}^{(\mathrm{g})}{ }_{1}\right)+c_{2} \mathrm{~L}^{(\mathrm{w})}{ }_{2}+c_{3} \mathrm{~L}^{(\mathrm{m})}{ }_{2}+c_{4} \mathrm{~L}^{(\mathrm{g})}{ }_{2}+c_{5} \mathrm{~L}^{(\mathrm{g})}{ }_{3}\right)$ and the available pollen $\mathrm{P}(\mathrm{t})$ at that time, where $c_{1}$ to $c_{5}$ are larval pollen consumption rates (a similar comparison was made for nectar as well.) We made a similar comparison between the number of larvae requiring care $\left(\mathrm{L}^{(\mathrm{w})}{ }_{1}+\ldots .+\mathrm{L}^{(\mathrm{g})}{ }_{3}\right)$ to the number of larvae the worker population can support (ZW, where $Z$ is the number of larvae a single worker can optimally care for) to determine whether or not proper feeding and care could be provided to the existing larvae by the available workers within the colony (Pomeroy 1979; Tasei et al. 2000); see Appendix 1 for more detail. The other form of population regulation within a hive was exhibited through oophagy, or the consumption of eggs by the worker or queen. Although this behavior is not strictly a population control measure, it can be a significant behavior when malnourishment occurs in the hive (Genissel et al. 2002). The degree of oophagy was calculated using a comparison between desired resource consumption and available resources, in the same way that larval ejection was calculated; values were then incorporated directly into egg laying rates in the model $b_{W}{ }^{*}(t), b_{M}{ }^{*}(t)$, and $b_{G}{ }^{*}(t)$. These functions represent the number of eggs laid at the time $t$ which will become larvae. Overall, these mechanisms yielded model expressions such as $b_{W}{ }^{*}(t-22) \exp \left[\Phi^{(W)}(t-18)-\Phi^{(W)}\right.$ $(t-9)]$, which represented new workers on day $t$ whose eggs were laid 22 days prior, having begun the larval phase 18 days before and survived to begin pupation 9 days previously.

We used the model to simulate toxicant effects in different scenarios that reflect documented impacts of pesticide exposure in the literature. In particular, we simulated (i) lethal direct effects on workers, (ii) sublethal effects via reduced foraging abilities and reduced brood sizes, (iii) combination of lethal and sublethal effects together (Feltham et al. 2014; Laycock et al. 2012; Laycock et al. 2014). We ran simulations for each of these situations measuring the cumulative reproductive output (males and gynes) as our primary metric of population effect. Initially the model was parameterized using values associated with Bombus terrestris, although we acknowledge that the model can accommodate other species of bumble bees with appropriate parameter values. To simulate acute effects of pesticide exposure, adult worker populations were culled at the time of exposure to the $\mathrm{LD}_{50}$. Exposure did not extend past the day it was introduced to the population. Next, we simulated the sublethal effect of reduced foraging ability, thereby reducing pollen and nectar resources available to the colony and measuring the resulting reproductive output. These effects were modeled by directly impacting the rates that adult workers collect pollen and nectar. We also simulated reductions in the initial broods, corresponding to a sublethal effect on the queen's egg-laying rate. The egg-laying rate was adjusted appropriately based on whether the first or second brood was affected by the colony's exposure to the pesticide and the overall reproductive output was measured. Finally, we simulated both lethal and sublethal effects and noted their combined effects on reproductive output.

\section{Results}

\section{Control}

In the absence of toxicological insult, the model produced an increase in the number of workers until around day 60 , after which workers declined and males and gynes (reproductives) increased nearly exponentially before plateauing off around 100 days after the start of the simulation. Pollen and nectar resource levels also declined between 70 and 80 days after the simulation, corresponding roughly with the decline in the worker population (Fig. 1).

\section{Lethal pesticide effects}

Acute pesticide effects were characterized as immediate reductions in the worker population corresponding to the $\mathrm{LD}_{50}$ dose of pesticide applied. We varied the time of exposure, noting the impact that delaying contact to pesticide may have on reproductive output. Simulation of an acute effect of pesticides on workers - corresponding to the $\mathrm{LD}_{50}$ - resulted in a marked decline of reproductive output when exposure to the toxicant occurred during the first 30 days of the simulation. However, results varied as a function of the timing of the exposure; application of the toxicant at 36 days after the start and beyond resulted in much less severe effects (Fig. 2).

\section{Sublethal pesticide effects}

The effect of resource reduction was severe for both pollen and nectar reduction levels above 20\%. Though these 
Fig. 1 Bumble bee colony simulation over 120 days, including dynamics for both resources, adult workers and cumulative adult reproductive members (males and gynes)
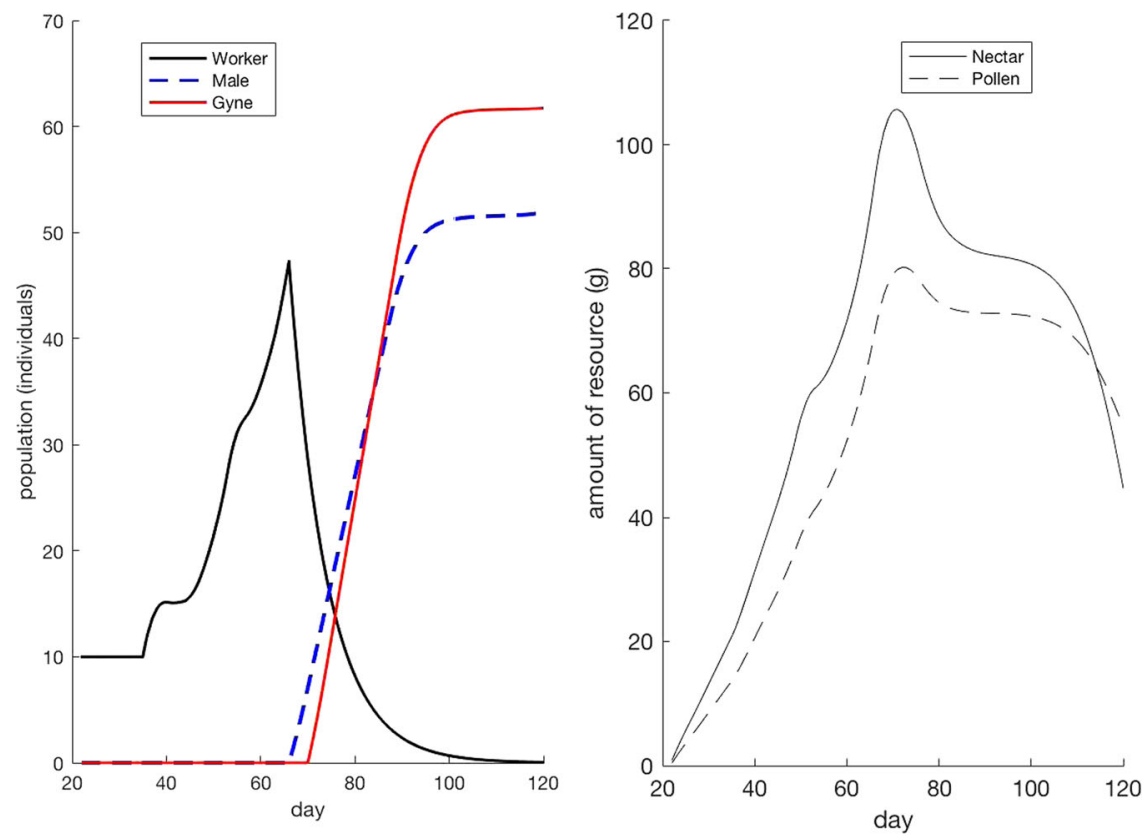

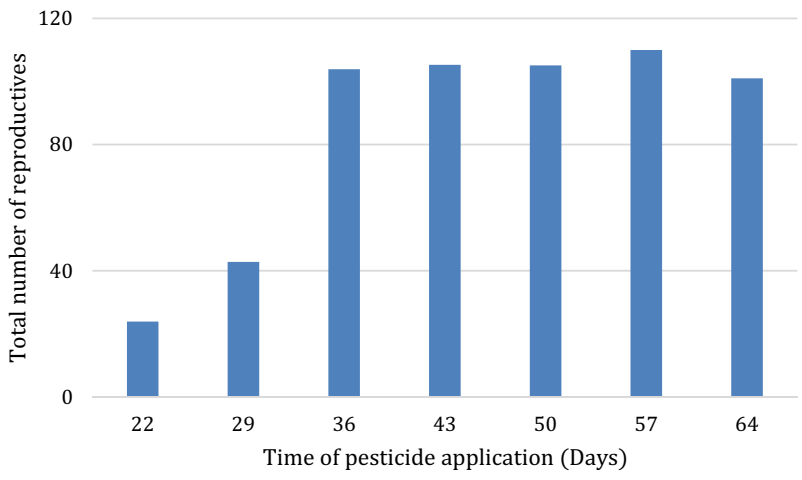

Fig. 2 Acute effects of $\mathrm{LD}_{50}$ dose on cumulative males and gynes produced in the colony as a function of the timing of pesticide application

effects were independent of each other, pollen reduction had a slightly more severe impact on reproductive output than nectar reduction (Fig. 3). Reductions in new brood (first and second broods together) greater than $10 \%$ corresponding to a sublethal effect on the queen's egg-laying rate resulted in severe declines in reproductive output. Also apparent reductions in the first brood due to exposure exacerbated the effects seen by a reduction in the second brood (workers that emerge on day 35) in Fig. 4. We emphasize this is an effect of fewer workers produced by the queen as opposed to any lethal exposure of workers to a pesticide.

\section{Lethal and sublethal effects combined}

Simulations of combinations of lethal and sublethal effects resulted in a non-linear interaction, demonstrating a

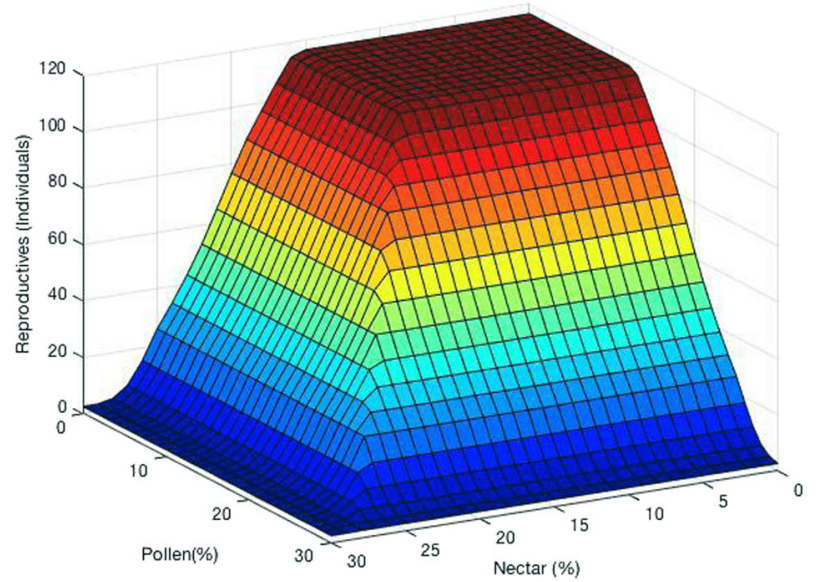

Fig. 3 Influence of sublethal effect of reducing foraging ability (by percentage) on bumble bee reproductive output (males + gynes)

synergistic effect. Declines in reproductives occurred after approx. $30 \%$ reductions solely due to lethal effects, or $20 \%$ solely in pollen reductions; the combination of these two levels resulted in nearly double the decline of reproductives (Fig. 5).

\section{Discussion}

The Millennium Ecosystem Assessment (2005) provided a conceptual framework for linking environmental health and human well-being; protection of ecosystem services such as biocontrol and crop pollination are central themes. In the past decade, significant efforts aimed at better understanding the effects of toxicants such as pesticides on 


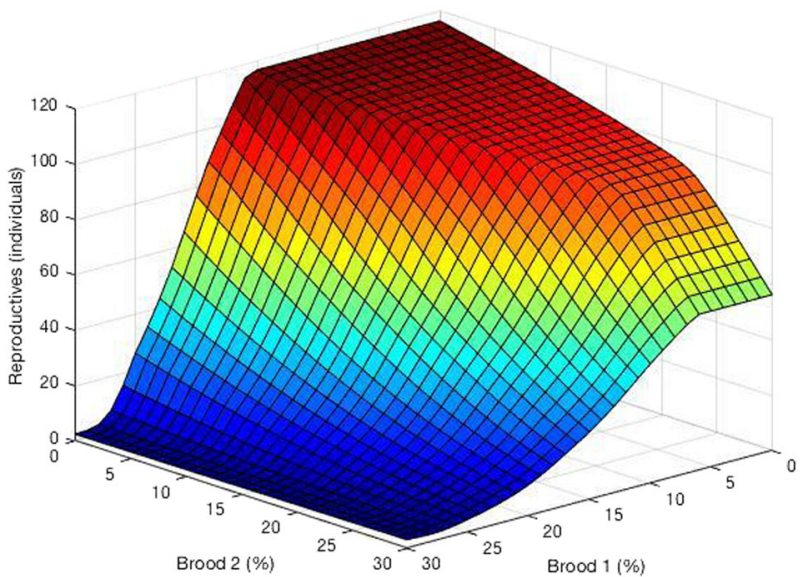

Fig. 4 The effect of sublethal reductions to egg laying rates (on 1st and 2nd broods) on cumulative reproductive output of the colony

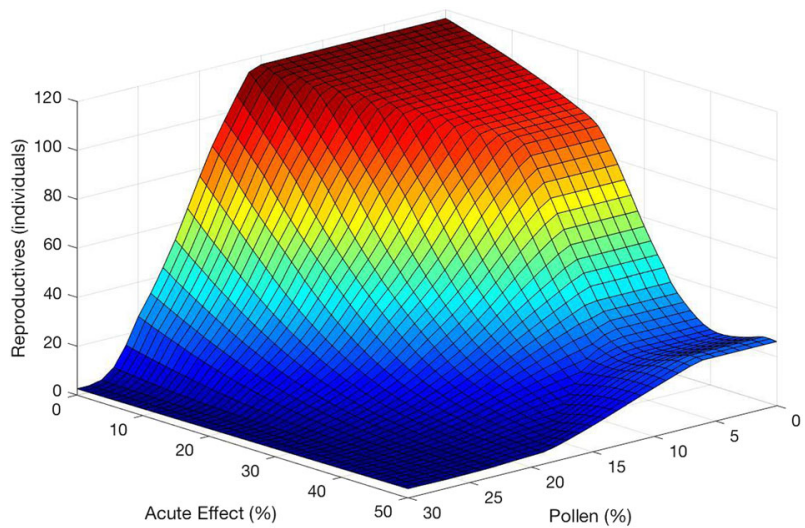

Fig. 5 Effects of combined lethal ("Acute") and sublethal ("Pollen" reduction) toxic insults on bumble bee reproductive output

hymenoptera-especially honeybees-have been made (Lundin et al. 2015). Although empirical studies on the effects of toxicants on non-Apis hymenoptera are increasing (e.g., Rundlöf et al. 2015; Stanley et al. 2016), assuming that our knowledge of one species' responses can be applied directly to other species risks creating confusion and misunderstandings (Banks et al. 2014). Recent physiological studies have corroborated this, demonstrating that pesticides such as pyrethroids affect honeybees (A. melifera) and bumble bees (B. terrestris) in fundamentally different ways (e.g., Kadala et al. 2019). Assessment and maintenance of the protection of ecosystem services relies fundamentally on a deep understanding of population dynamics; both empirical and theoretical approaches are important tools in this effort. Explorations of bumble bee population dynamics that incorporate our understanding of biological processes with predictive mathematical models provide a powerful means of prescribing protective measures and best practices. Here we have used a mechanistic model tailored to bumble bee colony development in an attempt to better understanding the response of bumble bees to toxicants such as pesticides. Our use of a delay differential equation model enables us to explicitly describe the effect of larval incubation and colony history on population outcomes. This level of detail allows us to demonstrate the sensitivity of colony viability to the timing and severity of pesticide sprays. Furthermore, the DDE model requires far fewer parameter estimations than approaches that use agent-based or individual-based models (e.g., Becher et al. 2014 2018). Empirical efforts that track real-time survivorship and behavior of larvae, workers and queens over a longer time period (similar to those conducted by Crall et al. $(2015,2018)$ but extended to larvae and for longer time periods would be useful for validating the DDE model presented here.

Understanding the mechanisms underlying the effects of resource availability on bumble bee population growth is an increasing focus of field and theoretical studies (Winfree et al. 2009; Williams et al. 2012); a recent study by Crone and Williams (2016) illustrates the importance of parsing out the relative importance of putatively important drivers (e.g., colony growth rates and floral resource availability) of bumble bee population outcomes. Less is known about combinations of reduced resource provisioning and diminished survivorship that may result from exposure to pesticides or mixtures of pesticides that have both lethal and sublethal effects, though the potential for multiplicative effects have been demonstrated in recent elegant experiments (e.g., Gill et al. 2012). Our simulations suggest that, even at low levels, sublethal effects such as reduced pollen foraging ability may result in severe declines in reproductive output if combined with lethal effects over $40 \%$, for instance (see Fig. 5). This underscores the importance of better understanding the effects of exposure to mixtures of toxicants.

In the current analysis, our model highlights several important aspects pertaining to population implications of pesticide exposure in bumble bees. First, the overall impact of acute effects such as those exhibited by an $\mathrm{LC}_{50}$ or $\mathrm{LD}_{50}$ dose varies greatly with timing of exposure, with pesticide applications later in the development of the colony having relatively little effect compared with applications imposed within the first 30 days (Fig. 2). The immediate reduction in workforce size prevents the same level of foraging as seen before pesticide exposure, thereby limiting the resources available to rear future broods. In addition, the reduced number of workers also results in neglected larvae which ultimately limits future brood sizes and further impacts the production of reproductive bees. Perry et al. (2015) similarly found that early reductions in foraging ability in honeybees could have dramatic impacts at the population level later on; they suggest that these types of delayed responses due to early stressors may help explain field 
observations and experiments documenting colony collapse disorder. Our model results likewise suggest that delays in pesticide applications could significantly lessen deleterious effects on bumble bee populations.

Second, sublethal effects on the population output due to reduced egg-laying rates may be lessened if reductions are kept below $10 \%$. However, higher levels of reduced egglaying rates in the first brood may interact synergistically with subsequent brood exposure (due to repeated exposure to the same pesticide, or exposure to another, different chemical), wreaking havoc on the population at higher levels even for low levels of reductions on the second brood (Fig. 4). Field studies exploring combinations of pesticides on bumble bee colony outcomes have revealed similar effects (e.g., Gill et al. 2012). Because bees in farmland mosaics are often exposed to multiple spray events, sometimes with multiple pesticides, these types of knock-on effects may be difficult to mitigate in practice.

The synergistic effects revealed in our simulations emphasize the need to carefully consider population endpoints when gauging risk to bumble bees from pesticides and other toxicants; none of these effects would be detectable from simple $\mathrm{LC}_{50}$ analyses. Taken together, our results suggest that more sophisticated mathematical treatments of population processes are critical for assessing mechanisms underlying the effects of pesticides on bumble bees. Particular attention should be paid to timing of pesticide exposure, as well as the specifics of combinations of pesticides to which bumble bee colonies might be exposed. Finally, empirical data should be generated to test and validate the specific outcomes predicted by the model.

Funding Funding was provided by the August T. Larsson Guest Researcher Programme at the Swedish University of Agricultural Sciences. This research was further supported in part by the Air Force Office of Scientific Research under grant numbers AFOSR FA955015-1-0298 and AFOSR FA9550-18-1-0457, and in part by the National Science Foundation under grant number RTG/DMS 1246991.

\section{Compliance with ethical standards}

Conflict of interest The authors declare that they have no conflict of interest.

Ethical approval This article does not contain any studies with human participants or animals performed by any of the authors.

Publisher's note Springer Nature remains neutral with regard to jurisdictional claims in published maps and institutional affiliations.

Open Access This article is licensed under a Creative Commons Attribution 4.0 International License, which permits use, sharing, adaptation, distribution and reproduction in any medium or format, as long as you give appropriate credit to the original author(s) and the source, provide a link to the Creative Commons licence, and indicate if changes were made. The images or other third party material in this article are included in the article's Creative Commons licence, unless indicated otherwise in a credit line to the material. If material is not included in the article's Creative Commons licence and your intended use is not permitted by statutory regulation or exceeds the permitted use, you will need to obtain permission directly from the copyright holder. To view a copy of this licence, visit http://creativecommons. org/licenses/by/4.0/.

\section{References}

Banks HT (2012) A functional analysis framework for modeling, estimation and control in science and engineering. CRC Press, Boca Raton, FL, ISBN 978-1-4398-8084-5

Banks HT, Banks JE, Bommarco R, Laubmeier AN, Myers NJ, Rundlöf M, Tillman K (2017) Modelling bumble bee population dynamics with delay differential equations. Ecol Model 351:14-23

Banks JE, Stark JD (1998) What is ecotoxicology? An ad-hoc grab bag or an interdisciplinary science? Integr Biol 5:1-9

Banks JE, Stark JD, Vargas RI, Ackleh AS (2011) Parasitoids and ecological risk assessment: can toxicity data developed for one species be used to protect an entire guild? Biol Control 59:336-339

Banks JE, Stark JD, Vargas RI, Ackleh AS (2014) Deconstructing the surrogate species concept: a life history approach to the protection of ecosystem services. Ecol Appl 24:770-778

Barbosa WF, De Meyer L, Guedes RNC, Smagghe G (2015) Lethal and sublethal effects of azadirachtin on the bumblebee Bombus terrestris (Hymenoptera: Apidae). Ecotoxicology 24:130-142

Bartomeus I, Ascher JS, Gibbs J, Danforth BN, Wagner DL, Hedtke SM, Winfree R (2013) Historical changes in northeastern US bee pollinators related to shared ecological traits. Proc Natl Acad Sci USA 110(12):4656-4660

Becher MA, Grimm V, Thorbek P, Horn J, Kennedy PJ, Osborne JL (2014) BEEHAVE: a systems model of honeybee colony dynamics and foraging to explore multifactorial causes of colony failure. J Appl Ecol 51(2):470-482

Becher MA, Twiston-Davies G, Penny TD, Gouldson D, Rotheray EL, Osborne JL (2018) Bumble-BEEHAVE: a systems model for exploring multifactorial causes of bumblebee decline at individual, colony, population and community level. J Appl Ecol 55:2790-2801

Biesmeijer JC, Roberts SP, Reemer M, Ohlemüller R, Edwards M, Peeters T, Schaffers AP, Potts SG, Kleukers R, Thomas CD, Settele J, Kunin WE (2006) Parallel declines in pollinators and insect-pollinated plants in Britain and the Netherlands. Science 313(5785):351-354

Biondi A, Zappalà L, Stark JD, Desneux N (2013) Do biopesticides affect the demographic traits of a parasitoid wasp and its biocontrol services through sublethal effects? PLoS ONE 8(9): e76548. https://doi.org/10.1371/journal.pone.0076548

Bommarco R, Lundin O, Smith HG, Rundlöf M (2011) Drastic historic shifts in bumble-bee community composition in Sweden. Proc R Soc Lond B 279:309-315

Brittain C, Potts SG (2011) The potential impacts of insecticides on the life-history traits of bees and the consequences for pollination. Basic Appl Ecol 12:321-331

Bryden J, Gill RJ, Mitton RAA, Raine NE, Jansen VAA (2013) Chronic sublethal stress causes bee colony failure. Ecol Lett 16:1463-1469

Crall JD, Gravish N, Mountcastle AM, Combes SA (2015) BEEtag: a low cost, image-based tracking system for the study of animal behavior and locomotion. PLoS ONE 10:e0136487. https://doi. org/10.1371/journal.pone.0136487pmid:2633221 
Crall JD, Switzer CM, Oppenheimer RL, Versypt AN, Dey B, Brown A, Eyster M, Guérin C, Pierce NE, Combes SA, de Bivort BL (2018) Neonicotinoid exposure disrupts bumblebee nest behavior, social networks, and thermoregulation. Science 362 (6415):683-6

Cresswell JE (2017) A demographic approach to evaluating the impact of stressors on bumble bee colonies. Ecol Entomol 42:221-229

Crone EE, Williams NM (2016) Bumble bee colony dynamics: quantifying the importance of land use and floral resources for colony growth and queen production. Ecol Lett 19:460-468

Desneux N, Decourtye A, Delpuech JM (2007) The sublethal effects of pesticides on beneficial arthropods. Annu Rev Entomol 52:81-106. https://doi.org/10.1146/annurev.ento.52.110405. 091440

Duchateau MJ, Velthuis HHW (1988) Development and reproductive strategies in B. terrestris colonies. Behavior 107(3):186-207

Feltham H, Park K, Goulson D (2014) Field realistic doses of pesticide imidacloprid reduce bumblebee pollen foraging efficiency. Ecotoxicology 23:317. https://doi.org/10.1007/s10646-014-1189-7

Forbes VE, Calow P, Grimm V, Hayashi TI, Jager T, Katholm A, Palmqvist A, Pastorok R, Salvito D, Sibly R, Spromberg J, Stark JD, Stillman RA (2011) Adding value to ecological risk assessment with population modelling. Hum Ecol Risk Assess 17:287-299

Genissel A, Aupinel P, Bressac C, Tasei JN, Chevrier C (2002) Influence of pollen origin on performance of $\mathrm{B}$. terrestris microcolonies. Entomol Exp Appl 104:329-336

Gill RJ, Ramos-Rodriguez O, Raine NE (2012) Combined pesticide exposure severely affects individual- and colony-level traits in bees. Nature 491(7422):105-8

Goulson D, Peat J, Stout JC, Tucker J, Darvill B, Derwent LC, Hughes WOH (2002) Can allotheism in workers of the bumblebee, Bombus terrestris, be explained in terms of foraging efficiency? Anim Behav 64:123-130

Goulson D, Nicholls E, Botías C, Rotheray EL (2015) Bee declines driven by combined stress from parasites, pesticides, and lack of flowers. Science 347. https://doi.org/10.1126/science.1255957

Hartung F, Krisztin T, Walther H, Wu J (2006) Functional differential equations with state-dependent delays: theory and applications. In: CaÑada A, DrÁbek P, Fonda A (eds) Handbook of differential equations: ordinary differential equations: Volume 3. Elsevier, Amsterdam

Häussler J, Sahlin U, Baey C, Smith HG, Clough Y (2017) Pollinator population size and pollination ecosystem service responses to enhancing floral and nesting resources. Ecol Evol 7:1898-1908

Kadala A, Charreton M, Charnet P et al (2019) Voltage-gated sodium channels from the bees Apismellifera and Bombus terrestris are differentially modulated by pyrethroid insecticides. Sci Rep 9 (1):1078. https://doi.org/10.1038/s41598-018-37278-z

Khoury DS, Barron AB, Myerscough MR (2013) Modelling food and population dynamics in honey bee colonies. PLoS ONE 8(5): e59084. https://doi.org/10.1371/journal.pone.0059084

Klein AM, Vaissiere BE, Cane JH, Steffan-Dewenter I, Cunningham SA, Kremen C, Tscharntke T (2007) Importance of pollinators in changing landscapes for world crops. Proc R Soc B 274:303-313

Klein S, Cabirol A, Devaud JM, Barron AB, Lihoreau M (2017) Why bees are so vulnerable to environmental stressors. Trends Ecol Evol 32(4):268-278

Lämsä J, Kuusela E, Tuomi J, Juntunen S, Watts PC (2018) Low dose of neonicotinoid insecticide reduces foraging motivation of bumblebees. Proc Biol Sci 285(1883):20180506. https://doi.org/ 10.1098/rspb.2018.0506

Laycock I, Lenthall KM, Barratt AT, Cresswell JE (2012) Effects of imidacloprid, a neonicotinoid pesticide, on reproduction in worker bumble bees (Bombus terrestris). Ecotoxicology 21 (7):1937-1945
Laycock I, Cotterell KC, O'Shea-Wheller TA, Cresswell JE (2014) Effects of the neonicotinoid pesticide thiamethoxam at fieldrealistic levels onmicrocolonies of Bombus terrestris worker bumble bees. Ecotoxicol Environ Saf 100:153-158

Lundin O, Rundlöf M, Smith HG, Fries I, Bommarco R (2015) Neonicotinoid insecticides and their impacts on bees: a systematic review of research approaches and identification of knowledge gaps. PLoS ONE 10(8):e0136928. https://doi.org/10.1371/journa 1.pone. 0136928

Manjon C, Troczka BJ, Zaworra M, Beadle K, Randall E, Hertlein G, Singh KS, Zimmer CT, Homem RA, Lueke B, Reid R, Kor L, Kohler M, Benting J, Williamson MS, Davies TGE, Field LM, Bass C, Nauen R (2018) Unravelling the molecular determinants of bee sensitivity to neonicotinoid insecticides. Curr Biol 28(7):1137-1143

MATLAB (2016a) The MathWorks, Inc. Natick, Massachusetts, United States

Murdoch WW, Nisbet RM, Blythe SP, Gurney WS, Reeve JT (1987) An invulnerable age class and stability in delay-differential parasitoid-host models. Am Nat 129(2):263-282

Millennium Ecosystem Assessment (2005) Ecosystems and human well-being: synthesis. Island Press, Washington, DC, ISBN 159726-040-1

Müller CB, Shykoff AJ, Sutcliffe GH (1992) Life history patterns and opportunities for queen-worker conflict in bumblebees (hymenoptera: Apidae). Oikos 65(2):242-248

Olsson O, Bolin A, Smith HG, Lonsdorf EV (2015) Modeling pollinating bee visitation rates in heterogeneous landscapes from foraging theory. Ecol Mod 316:133-143

Oster G (1976) Modeling social insect populations. I. Ergonomics of foraging and population growth in bumblebees. Am Nat 110 (972):215-245

Peat J, Goulson D (2005) Effects of experience and weather on foraging rate and pollen versus nectar collection in the bumblebee, Bombus terrestris. Behav Ecol Sociobiol 58(2):152-156

Pereboom JJM (2000) The composition of larval food and the significance of exocrine secretions in the bumblebee $B$. terrestris. Insect Soc 47(1):11-20

Perry CJ, Søvik E, Myerscough MR, Barron AB (2015) Rapid behavioral maturation accelerates failure of stressed honey bee colonies. Proc Natl Acad Sci USA 112(11):3427-3432

Phelps JD, Strang CG, Gbylik-Sikorska M, Sniegocki T, Posyniak A, Sherry DF (2018) Imidacloprid slows the development of preference for rewarding food sources in bumblebees (Bombus impatiens). Ecotoxicology 27(2):175-187

Pomeroy N (1979) Brood bionomics of Bombus ruderatus in New Zealand. Can Entomol 111(8):865-874

Ribeiro MF (1994) Growth in bumble bee larvae: relation between development time, mass, and amount of pollen ingested. Can J Zool 72(11):1978-1985

Ribeiro MF (1994) Growth in bumble bee larvae: relation between development time, mass, and amount of pollen ingested. Can J Zool 72(11):1978-1985

Rundlöf M, Andersson GK, Bommarco R, Fries I, Hederström V, Herbertsson L, Jonsson O, Klatt BK, Pedersen TR, Yourstone J, Smith HG (2015) Seed coating with a neonicotinoid insecticide negatively affects wild bees. Nature 521:77-80

Roger N, Michez D, Wattiez R, Sheridan C, Vanderplanck M (2017) Diet effects on bumblebee health. J Insect Phys 96:128-133

Shampine LF, Thompson S (2001) Solving DDEs in MATLAB. Appl Num Math 7:441-458

Stanley DA, Russell AL, Morrison SJ, Rogers C, Raine NE (2016) Investigating the impacts of field-realistic exposure to a neonicotinoid pesticide on bumblebee foraging, hosming ability and colony growth. J Appl Ecol 53(5):1440-1449

Stark JD, Banks JE (2003) Population-level effects of pesticides and other toxicants on arthropods. Annu Rev Entomol 48:505-519 
Stark JD, Banks JE, Vargas RI (2004) How risky is risk assessment? The role that life history strategies play in susceptibility of species to pesticides and other toxicants. Proc Natl Acad Sci USA 101:732-736

Stark JD, Vargas R, Banks JE (2007) Incorporating ecologically relevant measures of pesticide effect for estimating the compatibility of pesticides and biocontrol agents. J Econ Entomol 100:1027-1032

Stark JD, Vargas RI, Banks JE (2015) Incorporating variability in point estimates in risk assessment: bridging the gap between LC50 and population endpoints. Environ Toxicol Chem 34 (7):1683-1688

Switzer CM, Combes SA (2016) The neonicotinoid pesticide, imidacloprid, affects Bombus impatiens (bumblebee) sonication behavior when consumed at doses below the LD50. Ecotoxology 25 (6):1150-1159

Tan K, Chen W, Dong S, Liu X, Wang Y, Nieh JC (2015) A neonicotinoid impairs olfactory learning in Asian honey bees (Apis cerana) exposed as larvae or as adults. Sci Rep 5:10989
Tasei JN, Aupinel P (2008) Nutritive value of 15 single pollens and pollen mixes tested on larvae produced by bumblebee workers. Apidologie 39:397-409

Tasei JN, Lerin J, Ripault G (2000) Sub-lethal effects of imidacloprid on bumblebees, B. terrestris (Hymenoptera: Apidae), during a laboratory feeding test. Pest Manag Sci 56:784-788

Thorbek P, Campbell PJ, Thompson HM (2017) Colony impact of pesticide-induced sublethal effects on honeybee workers: a simulation study using BEEHAVE. Environ Toxicol Chem 36 (3):831-840

Williams NM, Regetz J, Kremen C (2012) Landscape-scale resources promote colony growth but not reproductive performance of bumble bees. Ecology 93(5):1049-1058

Winfree R, Aguilar R, Vázquez DP, LeBuhn G, Aizen MA (2009) A meta-analysis of bees' responses to anthropogenic disturbance. Ecology 90(8):2068-2076

Wratten SD, Gillespie M, Decourtye A, Mader E, Desneux N (2012) Pollinator habitat enhancement: benefits to other ecosystem services. Agric Ecosyst Environ 159:112-122 